\title{
FURTHER DEVELOPMENT OF A COMMERCIAL DRIVING SIMULATION FOR RESEARCH IN OCCUPATIONAL MEDICINE
}

\section{AXEL MUTTRAYㄹ, ANAIS BREITINGER ${ }^{1 *}$, ELISABETH GOETZE ${ }^{1 *}$, THOMAS SCHNUPP², BRITTA GEISSLER ${ }^{1}$, THOMAS KAUFMANN ${ }^{3}$, MARTIN GOLZ ${ }^{2}$, and STEPHAN LETZEL ${ }^{1}$}

\author{
${ }^{1}$ Institute of Occupational, Social and Environmental Medicine, Mainz, Germany \\ University Medical Center of the Johannes Gutenberg University of Mainz \\ ${ }^{2}$ University of Applied Sciences Schmalkalden, Schmalkalden, Germany \\ Faculty of Informatics \\ ${ }^{3}$ Institute of Forensic Medicine, Mainz, Germany \\ University Medical Center of the Johannes Gutenberg University of Mainz
}

\begin{abstract}
Objectives: The purpose of this study was to refine a commercial car driving simulation for occupational research. As the effects of ethanol on driving behavior are well established, we choose alcohol as a test compound to investigate the performance of subjects during simulation. Materials and Methods: We programmed a night driving scenario consisting of monotonous highway and a rural road on a Foerst F10-P driving simulator. Twenty healthy men, 19-30 years, participated in a pilot study. Subjects were screened for simulator sickness, followed by training on the simulator one hour in total. Experiments were performed in the morning on a separate day. Participants were randomized into either an alcoholized or a control group. All subjects drove two courses consisting of highway and rural road and were sober for the first course. During a $1 \mathrm{~h}$ break the ethanol group drank an alcoholic beverage to yield $0.06 \%$ blood alcohol concentration (BAC). Generalized linear mixed models were used to analyze the influence of alcohol on driving performance. Among others, independent variables were Simulator Sickness Questionnaire scores and subjective sleepiness. Results: Subjects did not experience simulator sickness during the experiments. Mean BAC before the second test drive was $0.065 \%$ in the mildly intoxicated group. There was no clear-cut difference in the number of crashes between 2 groups. BAC of $0.1 \%$ would deteriorate mean braking reaction time by $237 \mathrm{~ms}(\mathrm{SE}=112, \mathrm{p}<0.05)$. Ethanol slightly impaired the tracking in the righthand curves $(\mathrm{p}=0.058)$. Braking reaction time improved by $86 \mathrm{~ms}(\mathrm{SE}=36, \mathrm{p}<0.05)$ for the second test drive, indicating a learning effect. Conclusions: In sum, a clear ethanol effect was observed in the driving simulation. This simulation seems suitable for occupational research and produces little simulator sickness. Controlling for possible learning effects is recommended in driving simulation studies.
\end{abstract}

Key words:

Driving simulator, Braking reaction time, Lane keeping behavior, Simulator sickness, Learning effect, Ethanol

\footnotetext{
* The paper contains data from the medical dissertations of marked authors, in preparation. Received: June 26, 2012. Accepted: December 1, 2013.

Corresponding author: A. Muttray, Universitätsmedizin der Johannes Gutenberg-Universität Mainz, Institut für Arbeits-, Sozial- und Umweltmedizin, Obere Zahlbacher Straße 67, D-55131 Mainz, Germany (e-mail: amuttray@uni-mainz.de).
} 


\section{INTRODUCTION}

Driving simulators can be used in occupational medicine for research, education and rehabilitation [1], as they provide a safe alternative to on-road testing. Driver sleepiness is one matter of interest. It is suggested to be the primary cause of about $25 \%$ of fatal accidents on the German autobahn (highway) [2]. The results of international studies are in the same order of magnitude [3-6]. Subjects suffering from obstructive sleep apnea syndrome are at an increased risk for a motor vehicle accident due to sleepiness [7]. Treatment with continuous positive airway pressure (CPAP) reduces that risk [8,9]. A meta-analysis suggests that driving simulation is a suitable method to evaluate the therapeutic effects of continuous positive airway pressure in subjects with obstructive sleep apnea syndrome [9].

Occupational exposure to organic solvents can be high at different workplaces, especially in small companies and in craft enterprises. Depending on the respective biological half-lifes, solvent effects on the central nervous system may persist beyond the end of shift. Impairment of psychomotor functions is one important acute solvent effect among others and can be relevant to drivers. In a large study the association between exposure to gasoline vapors and commuting accidents after shift was investigated [10]. A reduction of occupational solvent exposure was related to a decrease of commuting injuries on journeys back home for gasoline workers. Results from an epidemiological study may provide an association, but no proof of causal relationship. A standardized experiment including driving simulation might support a toxicological argument for the validity of the observed statistical association. Apart from volatile organic solvents, ethanol and many medications may also impair driving ability $[11,12]$.

These examples highlight some relevant applications of driving simulators in occupational and clinical medicine. Normally, clinicians and researchers are not able to construct a driving simulator themselves, but rely on commercial systems. Commercial simulators are constructed for special purposes, e.g. education. Their configuration does not necessarily meet the specific needs of the user. The aim of this study was to refine a commercial driving simulation for research in occupational and traffic medicine. Using a driving scenario, methodological issues must be considered, too. An inherent drawback of driving simulators is simulator sickness, which is more or less experienced by some subjects with an intact vestibular system. Simulator sickness develops without true motion. Its symptoms overlap with those of motion sickness. Major symptoms of motion sickness involve gastrointestinal stress including burping, nausea and emesis. For simulator sickness, less gastrointestinal but more visual symptoms like eyestrain and blurred vision have been reported [13]. Kind and severity of simulator sickness symptoms both depend on individual factors and properties of the driving scenario $[1,13]$. In a number of published experiments, driving performance has not been controlled for simulator sickness. As simulator sickness may impair driving performance, precautions must be taken. First of all, the scenario should be constructed in a way that simulator sickness is not induced in the majority of subjects. Furthermore, drivers must be monitored for possible symptoms of simulator sickness. The Simulator Sickness Questionnaire (SSQ) is considered to be the gold standard for monitoring [1,13,14].

This study includes two working packages. The first was to refine a commercial driving simulation. After completion of this work a pilot study was performed. Ethanol was chosen to investigate driving performance because its effects on simulator drivers are well established $[15,16]$. Our investigation of performance focuses on accidents, braking reaction time and tracking performance.

\section{METHODS}

\section{Experimental design}

The pilot study was performed according to a parallel group design. Twenty healthy young male volunteers were selected and assigned randomly to either an 
alcoholized or a sober control group. On the first day after a medical screening, training sessions were conducted on the driving simulator. The experiment itself took place some days later. All subjects drove a course consisting of a 32 min highway (German autobahn) and a 32 min rural drive in a state of soberness. During $1 \mathrm{~h}$ rest they either drank diluted vodka or pure orange juice. Target concentration of blood alcohol level was $0.06 \%$. Then subjects drove an analog course. Subjective sleepiness, possible symptoms of simulator sickness and driving behavior were monitored.

\section{Study subjects}

Twenty healthy male subjects (age: $19-30$ years, mean: 25 ) were recruited by advertisements at the university. Medical examinations included tests like visual acuity and color vision ability according to the German Guidelines for Occupational Medical Examinations (Guideline 25 Driving, Controlling and Monitoring Work) [17]. The subjects were in possession of a driver's license for at least one year and had at least $5000 \mathrm{~km}$ of driving experience. All subjects were social drinkers. Exclusion criteria were alcohol abstinence, alcohol abuse, kinetosis, simulator sickness, liver disease, diseases and intake of medications which might affect driving ability, capacity of reaction, and the effects of ethanol. Sleep disorders and daytime sleepiness were exclusion criteria, too. Scores on the Epworth Sleepiness Scale were not elevated (i.e. $\leq 9$ [18]). Participants rated their subjective alcohol tolerance using a $100 \mathrm{~mm}$ visual analog scale (VAS) with a left anchor labeled "absolutely nothing" and a right anchor labeled "a lot of alcohol". Mean tolerance of the ethanol group was $61.3 \mathrm{~mm}(\mathrm{SD}=10.3)$, the respective value of the control group $52.5 \mathrm{~mm}(\mathrm{SD}=16.1)$. Subjects were required to abstain from alcohol consumption for the respective days before training and measurements. Breath alcohol concentrations (Draeger Alcotest $6510^{\circledR}$, Draeger Safety AG, Germany) were below the detection limit upon arrival at the lab. Additionally, a urine drug screening (MAHSAN Kombi/DOA 10®, Mahsan Diagnostika, Germany) was performed at the beginning of each day. Tests did not show any signs of drug intake. Subjects were also instructed to abstain from caffeinated beverages. Analysis of caffeine in saliva specimens (analytical method derived from [19]) confirmed that subjects had not drunken any caffeinated beverages before the experiments. Moderate smoking was no exclusion criteria if the subjects were able to abstain from smoking during the experiments without any withdrawal symptoms. Two smokers were in each subgroup. One subject was replaced because he did not pass the screening course on simulator sickness. The study was approved by the local ethics committee and it was performed according to the Declaration of Helsinki and its latest amendments. Subjects gave written informed consent and were paid for participation.

\section{Driving simulation}

Driving simulator and scenarios

The driving simulator used in this study is a fixed-base Foerst model F10-P(Dr.-Ing. Reiner Foerst GmbH, Wiehl, Germany). The vehicle controls are similar to an actual car (Ford Fiesta) with an automatic gearbox. A sound system generates noises related to speed and collisions. The system generates a realistic roadway scenery which is projected on a screen $(1.80 \mathrm{~m}$ by $1.39 \mathrm{~m})$. The manufacturer provided different driving scenarios. However, they were not suitable for our research purpose as a long lasting monotonous scenario was missing. Preliminary tests indicated that some graphic elements were liable to induce simulator sickness in average sensitive subjects. The manufacturer provided a programming tool enabling the combination of predefined road segments, including surroundings, resulting in new driving scenarios. We constructed different scenarios for the screening of simulator sickness, familiarization with the simulator, training, and for two experimental sessions simulating night. Programming 
was performed according to the manufacturer's manual. Subjects were instructed to obey all traffic rules, including line markings. Driving behavior was monitored by means of a video system (Videoworkstation, Dr.-Ing. D. Sommer, Schmalkalden, Germany). The simulator was in an air-conditioned and quiet room (temperature: $20.8 \pm 1.4^{\circ} \mathrm{C}$ (SD), humidity: $37.5 \pm 7.1 \%$ ).

To screen for simulator sickness, ten full braking maneuvers on the rural road were used because they result in more intense visual-vestibular conflicts than average driving.

The environmental conditions in the training and the experimental sessions were identical. Night scenarios were chosen to reduce the risk of simulator sickness. Drivers had a clear view of the road and the traffic. The lanes were dry. Each training and experimental session started with a highway course. The highway had two lanes in each direction and was straight. We had to spare curves, because all curves contained poorly designed bridges. As the car had a little tendency to deviate rightwards, the drivers were forced to steer. Speed limit was $130 \mathrm{~km} / \mathrm{h}$, indicated by road signs every $2 \mathrm{~km}$. At the end of the highway drive, subjects had to stop because of traffic congestion.

After passing the congestion, subjects took the next exit and continued the test drive on a rural road. It consisted of straight sections and slightly curved bends to the left and right. The roads had white lane markings and reflectors at the roadsides. Speed limit was $100 \mathrm{~km} / \mathrm{h}$. Subjects were instructed to drive $100 \mathrm{~km} / \mathrm{h}$ on the straight sections. Three different dangerous situations were simulated to measure braking reaction time. Braking reaction time was measured only in straight sections in order to reduce the risk of simulator sickness. Single deers, donkeys, and men (joggers) ran onto the road (Figure 1).

Then, subjects had to hit the brakes to avoid a collision and keep the lane. Objects were inserted at predefined positions of the rural road when the car approached. The distance from the car to each object, which was covered by

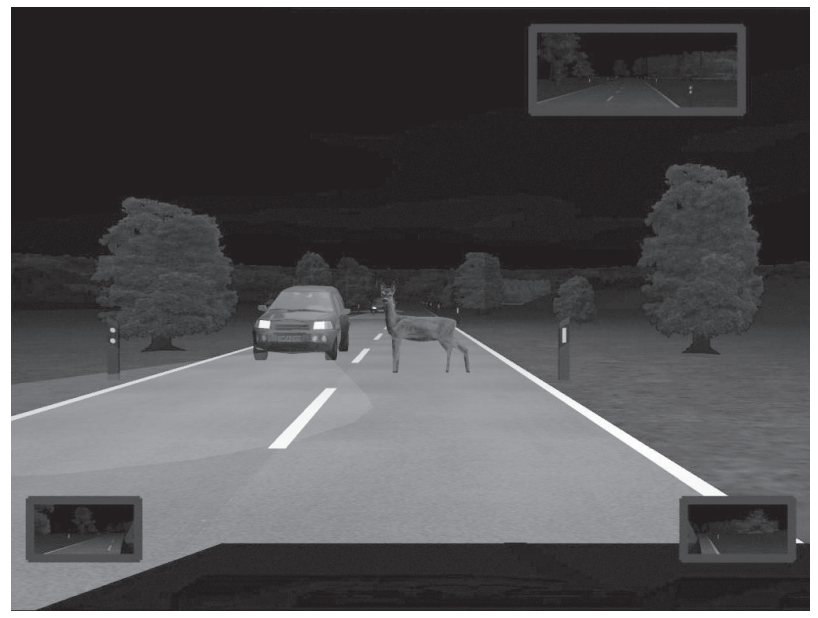

The subject has to hit the brakes and maintain within lane to avoid an accident.

Fig. 1. A deer crosses the road

a bush before starting, was fixed depending on preliminary experiments with fit, rested young drivers. The distances were set in such a way that attentive test drivers were able to avoid a collision. The distance was $80 \mathrm{~m}$ for the animals. Ninety meters were necessary for the object "man" to avoid a crash because he was faster than the animals. The deer's contrast to the surroundings was stronger than that of the donkey. The man's shirt was bright and thus the contrast was the highest. Measurement of braking reaction time started when the center of the respective object was visible and was finished when the test subject hit the brakes. Whenever a collision occurred, the scenario stopped and the driver was alerted by the noise of the crash. Subsequently, the car was placed back in the middle of the right traffic lane. The subject had to restart the car and the test continued.

Each of the two training sessions consisted of a $3 \mathrm{~min}$ monotonous highway drive and a $20 \mathrm{~min}$ rural drive. Six dangerous situations (2 deers, 2 donkeys, and 2 men) were simulated to measure braking reaction time in each rural road course. The experimental driving contained a monotonous $32 \mathrm{~min}$ highway course and a $32 \mathrm{~min}$ rural course. At the end of the highway drive, subjects had to 
stop because of traffic congestion. Two similar $32 \mathrm{~min}$ rural road courses were programmed for the first and second experiment. Twelve dangerous situations were simulated to measure the braking reaction time in each rural road course. It was intended to insert four objects of each kind (deer, donkey, and men, respectively) in each rural road course. Due to a programming error, which was recognized after starting the experiments, 5 deers, 4 donkeys and 3 men were inserted in the second course.

\section{Performance measures}

Crashes and reaction time were registered. Lane keeping behavior was assessed by the standard deviation in lane position (Sdlat). Sdlat is a well-established method to assess tracking performance, e.g. Arnedt et al., Boyle et al., and Risser et al. [20-22]. Basically, Sdlat represents the standard deviation of the car's lateral position in the lane in relation to its mean lateral position. It is possible to either calculate the mean lane position and subsequently Sdlat over the whole test or individually over segments [23]. The first approach leads to a raised probability of falsepositive impairment detection due to stable and intended shifts of the mean lane position by the driver [23]. Additionally, since the scenario is constructed by concatenating pre-defined road segments, the second approach was utilized. No additional segmentation was applied. Since subjects had been instructed to keep on the right lane of the highway course, lane changes biasing Sdlat need not to be interpreted.

\section{Assessment of subjective symptoms}

Sleepiness was assessed by the Karolinska Sleepiness Scale (KSS) [24]. This ordinal scale ranges from 1 (very alert) to 9 (very sleepy, fighting sleep, an effort to keep awake). Possible symptoms of simulator sickness were assessed by the Simulator Sickness Questionnaire (SSQ) [14]. The questionnaire comprises 16 items which have to be rated on a 4-level Likert-type scale. If subjects reported symptoms of possible simulator sickness, they were asked for a detailed verbal description. Subjects rated their perceived degree of impairment after drinking using a VAS. The scale consisted of a 100-mm line with two opposing end points, i.e. none and most intense (drunken).

\section{Ethanol administration \\ and control of blood alcohol concentration}

Previous research has revealed a considerable interindividual variation in the effects of ethanol [16]. The rationale for the target concentration of $0.06 \%$ alcohol is as follows: On the one hand, a sufficient concentration is necessary to assure the effects of ethanol on driving behavior. On the other hand, subjects should not become inebriated. This may be the case even at $0.08 \%$, if subjects are used to ingesting only little doses of ethanol. Therefore, participants received an amount of ethanol to approximate a peak level of $0.06 \%$. The amount administered was calculated according to the Widmark equation [25]. Vodka was diluted with orange juice. The beverage was consumed within $40 \mathrm{~min}$. Twenty min later breath alcohol concentration was tested by a breath analyzer (Alcotest 6510, Dräger, Lübeck, Germany). If the estimated $\mathrm{BAC}$ was too low, subjects drank another aliquot. In this case, BAC was controlled again after $30 \mathrm{~min}$ by breath analyzer. Control subjects drank pure orange juice. After the driving session, breath alcohol concentration was measured again and a venous blood sample was taken to determine BAC by gas chromatography.

\section{Experimental procedure}

Subjects arrived at 8 a.m. after a night of regular sleep at each day. The first day for screening and training started with a medical check-up. Before driving, subjects removed their watches and turned off their mobile phones. Then subjects were familiarized with the driving simulator and had to pass a screening course checking for simulator sickness. Driving in a virtual environment needs some time 
for adaptation. In this study, training consisted of a demonstration course with different reaction tests including intended crashes. Then subjects drove two training courses. On each rural road drive subjects performed a total of 6 reaction tests. Including the demonstration course, subjects carried out 16 reaction tests with full braking.

The second, experimental day started with a medical check at 8 a.m. After that, subjects completed the KSS and SSQ questionnaires and drove a 32 min highway course and a 32 min rural road course. KSS and SSQ questionnaires were filled out after every highway and rural road drive. Subjects also reported the maximum of perceived sleepiness during the respective previous test drive. During the following break, subjects drank orange juice with or without vodka. After controlling breath alcohol concentration, subjects filled out KSS and SSQ questionnaires again and rated their perceived degree of impairment after drinking on a VAS (100 mm, sober - impaired). Additionally, the self-rated roadworthiness was also assessed using a VAS (100 mm, no fit to drive - fully fit to drive). Then the second experimental course was performed analogous to the first.

\section{Statistics}

Firstly, the variables: blood alcohol concentration, subjective driving ability, simulator sickness, the number of accidents, braking reaction time, Sdlat, and subjective sleepiness were analyzed descriptively. In addition, the control group's sleepiness scores during and after the highway drives and the respective scores obtained during and after the rural road drives were compared by using sign tests.

To analyze the influence of alcohol on driving performance, multiple linear mixed models were used. The errors are assumed uncorrelated over time with homogeneous variance. Dependent variables were mean individual braking reaction time and Sdlat. As lateral control is different in straight sections and bends [20], the rural road was separated into straight sections, right- and left-hand bends for further analyses. Length of the respective rural road segments was $200 \mathrm{~m}, 380 \mathrm{~m}$, and $410 \mathrm{~m}$. Segments including reaction time tasks and the ones following up were omitted. A straight segment of the highway comprised $480 \mathrm{~m}$. The resulting set of Sdlat measurements could not be fed into the multiple linear mixed models for a repeated measurement design with two successive test drives. Instead, we had to compute one scalar score for Sdlat as a measure of tracking ability for each test drive and type of road segment.

First, the 90th percentiles of all Sdlats of highway segments were calculated for each subject. This percentile was chosen since greater deviations of the lane position are more relevant to accident risk than minor ones. Afterwards the fraction of segments whose Sdlat scores exceeded this percentile was calculated, yielding an individual score. These scores were fed into a multiple linear mixed model. The same procedure was performed for the straight sections, and the right- and left-hand bends of the rural road. Additionally, calculations were performed with scores derived from the 50th and 75th percentiles. Due to a manufacturer's programming error, Sdlat on the rural road could only be evaluated for 17 subjects.

The other variables were independent (Table 1). Experimental sessions were categorical variables with the 1 st session as reference. The triggers for a braking reaction (deer, donkey, and man) were also categorical variables with the deer as reference. The numbers of the three objects in the two sessions have been considered in the statistical model with reaction time as dependent variable. The other variables were continuous. Random intercept models were used to account for heterogeneity between individuals and within individual correlations. Appropriate t-tests/F-tests of the fixed effects were performed; $p$ values are two-sided. All analyses are explorative; $p$-values are presented only for descriptive purposes and were not adjusted for multiple testing. Statistical calculations were performed using SPSS package (release 17). 
Table 1. Effects of ethanol on braking reaction time on the rural road (linear mixed model, $\mathrm{N}=20$ )

\begin{tabular}{|c|c|c|c|}
\hline \multirow[t]{2}{*}{ Parameter } & \multicolumn{2}{|c|}{$\begin{array}{l}\text { Effects of ethanol } \\
\text { on braking reaction time }\end{array}$} & \multirow[t]{2}{*}{$\mathrm{p}$} \\
\hline & estimate (s) & SE (s) & \\
\hline Intercept & 1.216 & 0.193 & $<0.001$ \\
\hline Session 1 & $-* *$ & - & - \\
\hline Session 2 & -0.086 & 0.036 & 0.018 \\
\hline Deer* & $-* *$ & - & - \\
\hline Donkey* & 0.398 & 0.025 & $<0.001$ \\
\hline Man* & 0.601 & 0.025 & $<0.001$ \\
\hline Blood alcohol level (\%) & 2.369 & 1.122 & 0.037 \\
\hline Alcohol tolerance (ordinal scale 0-100) & -0.003 & 0.002 & 0.146 \\
\hline \multicolumn{4}{|l|}{ Karolinska Sleepiness Scale score } \\
\hline at arrival & -0.300 & 0.039 & 0.458 \\
\hline before the 1 st test drive & -0.017 & 0.020 & 0.393 \\
\hline maximum on highway & -0.034 & 0.029 & 0.238 \\
\hline at the end of highway & 0.047 & 0.028 & 0.102 \\
\hline maximum on rural road & 0.073 & 0.025 & 0.005 \\
\hline after rural road & -0.102 & 0.035 & 0.005 \\
\hline \multicolumn{4}{|l|}{ Simulator Sickness Questionnaire score } \\
\hline at arrival & -0.021 & 0.025 & 0.411 \\
\hline before the 1 st test drive & -0.005 & 0.005 & 0.295 \\
\hline at the end of highway & 0.000 & 0.003 & 0.997 \\
\hline after rural road & 0.004 & 0.004 & 0.314 \\
\hline
\end{tabular}

* Objects to react to.

** Reference.

$\mathrm{SE}$ - standard error.

\section{RESULTS}

\section{Blood alcohol concentration and perceived effects}

Mean estimated BAC, determined by a breath analyzer, was $0.065 \%$ (SD $=0.005 \%$, minimum: $0.057 \%$, maximum: $0.073 \%$ ) before the second test drive. The respective values after the second drive were $0.047 \%$ ( $\mathrm{SD}=0.007 \%$, minimum: $0.037 \%$, maximum: $0.059 \%$ ). Real mean BAC was $0.048 \%$ (SD $=0.007 \%$, minimum: $0.040 \%$, maximum: $0.060 \%$ ) at this point of time. Real and estimated BAC were highly correlated (Pearson $\mathrm{r}=0.977, \mathrm{p}<0.001)$. Median degree of general impairment due to ethanol consumption was 64 (range: 37-71 (VAS 0-100 mm)). At that time, alcoholized subjects rated their median driving ability 20 (range: 1-59). Values of the control group were 90 (76-100), respectively.

\section{Subjective sleepiness}

KSS scores were highest during highway drives in both groups, especially during the second test drive (Table 2). With respect to a possible impact of sleepiness on the 
Table 2. Subjective sleepiness scores, measured by the Karolinska Sleepiness Scale (KSS)

\begin{tabular}{|c|c|c|}
\hline & Ethanol group & Control group \\
\hline Time & $\begin{array}{c}\mathrm{Me} \\
\text { (1st and 3rd quartile) } \\
(\mathrm{N}=10)\end{array}$ & $\begin{array}{c}\mathrm{Me} \\
\text { (1st and 3rd quartile) } \\
(\mathrm{N}=10)\end{array}$ \\
\hline At arrival (all subjects were sober) & $3(2.75,3)$ & $3(2,3.25)$ \\
\hline Before the 1 st test drive & $3(2.75,3)$ & $3(2,3.25)$ \\
\hline Maximum on highway & $4.5(3.75,7)$ & $5(3.75,6)$ \\
\hline At the end of highway & $4(3,6.25)$ & $4(3.75,6)$ \\
\hline Maximum on rural road & $4.5(3,5.5)$ & $4(3,5.25)$ \\
\hline After rural road & $3.5(3,5.5)$ & $4(3,5)$ \\
\hline Break (subjects drank ethanol or pure juice) & - & - \\
\hline Before the 2 nd test drive & $3(3,4.25)$ & $3.5(2.75,4.25)$ \\
\hline Maximum on highway & $5.5(4,8)$ & $6.5(3.75,8)$ \\
\hline At the end of highway & $4.5(3.75,7.25)$ & $6(3,7)$ \\
\hline Maximum on rural road & $3.5(3,6.25)$ & $4.5(3,5.5)$ \\
\hline After rural road & $3(3,5.25)$ & $3(3,6)$ \\
\hline
\end{tabular}

KSS - ordinal scale from 1 to 9.

Me - median.

SSQ scores, the corresponding KSS scores of the control group's second test drives on the highway and rural road were compared. Median scores of the maximum perceived sleepiness on the highway and rural road were 6.5 and 4.5 $(\mathrm{p}=0.070$ sign test, $\mathrm{N}=10)$. Respective scores after the highway and rural road drives were 6 and 3 ( $p=0.125$, sign test, $\mathrm{N}=10$ ).

\section{Simulator sickness}

No subject had to terminate the experiment due to symptoms of possible simulator sickness, not even after ethanol ingestion (Figure 2). Obviously, SSQ scores of the control group were higher after the second highway drive than after the following rural road drive (Figure 2a). Since the highest sleepiness scores were associated with the highway drives (Table 2), we additionally calculated a sum score without the item "fatigue". The difference between the sum scores on the highway and rural road disappeared only partially (data not shown). If both the scores of "fatigue" and "difficulty concentrating" were omitted from the calculation of the sum scores of sober subjects, the resulting sum scores would not be higher on the highway on the first course (Figure 2a). A slight difference remained with respect to the sum scores obtained from the second course (Figure 2a).

\section{Performance of subjects}

Accidents

No accidents with crash barriers on the highway or oncoming traffic on the rural road were observed. Crashes with reflector posts on the rural road could not be correctly counted due to a manufacturer's programming error. Table 3 gives an overview of the crashes during reaction tasks. In the ethanol group, the total number of accidents went up slightly from 25 in the first test drive to 28 in the second one, whereas the control group displayed a decrease from 29 to 20. Most of the low-contrast donkey events resulted in accidents (Table 3 ). 

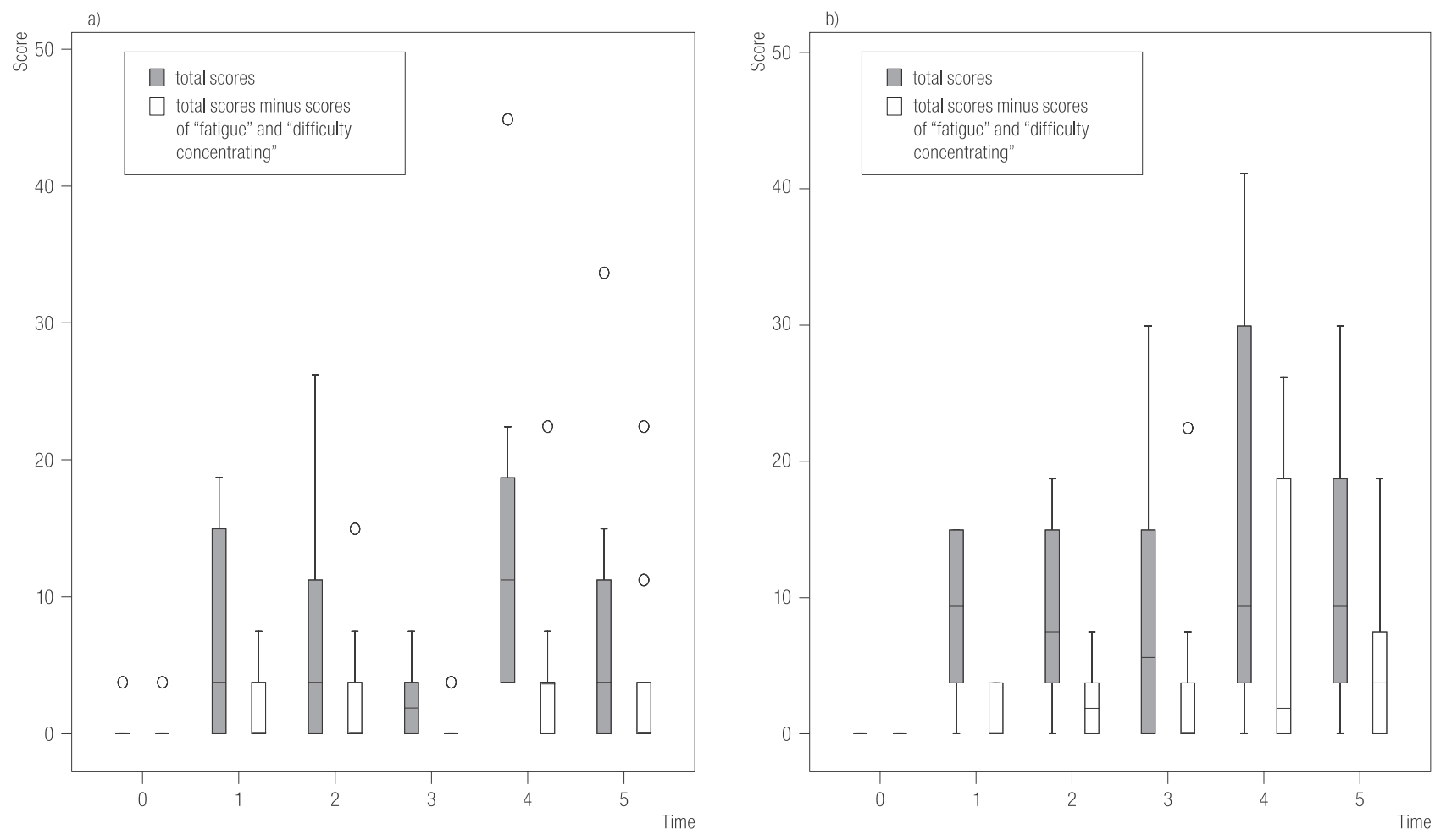

a) control group; b) ethanol group, subjects drank ethanol before the 2nd test drive.

Time: 0 - before start, 1 - at the end of highway, 2 - after rural road, 3 - after rest, before the second test drive, 4 - at the end of highway, 5 - after rural road.

Fig. 2. Simulator Sickness Scores of control and alcoholized subjects (each N = 10)

Table 3. Accidents during braking reaction time test (rural road, $\mathrm{N}=20$ )

\begin{tabular}{lcccc}
\hline & \multicolumn{2}{c}{$\begin{array}{c}\text { Crashes in ethanol group } \\
\text { (n) }\end{array}$} & \multicolumn{2}{c}{$\begin{array}{c}\text { Crashes in control group } \\
\text { (n) }\end{array}$} \\
\cline { 2 - 5 } & 1st test drive (sober) & $\begin{array}{c}\text { 2nd test drive } \\
\text { (intoxicated) }\end{array}$ & 1st test drive (sober) & 2nd test drive (sober) \\
\hline Deer & 3 & 6 & 5 & 1 \\
Donkey & 18 & 16 & 19 & 17 \\
Man & 4 & 6 & 5 & 2 \\
Total & 25 & 28 & 29 & 20 \\
\hline
\end{tabular}

Due to a programming error, which was recognized after starting the experiments, 5 deers, 4 donkeys and 3 men were inserted in the second course instead of 4 each.

\section{Braking reaction time}

Braking reaction time varied considerably (Figure 3). According to the linear mixed model, $0.1 \%$ BAC would increase the reaction time by $237 \mathrm{~ms}$ (Table 1). On average, the reaction time for the donkey was $398 \mathrm{~ms}$ longer than for the deer. The longest reaction time was measured for the man; it was $601 \mathrm{~ms}$ longer compared to that for the deer. 

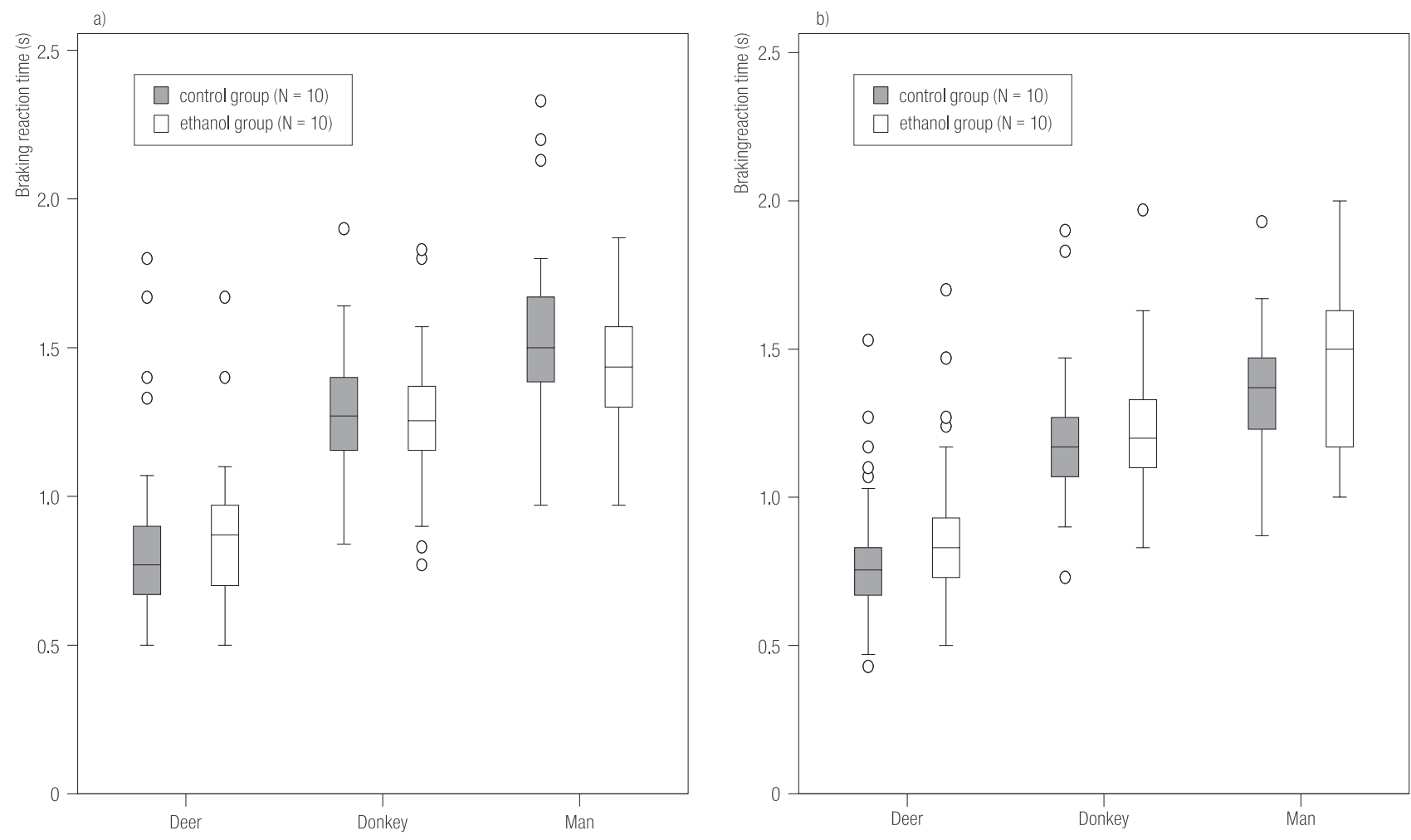

a) first test drive (all subjects were sober).

b) second test drive.

Fig. 3. Braking reaction time

\section{Lane keeping behavior}

Sdlat measures the driver's ability to maintain lane position. Sdlat was lowest in the straight rural road sections and highest in the left-hand curves (Figure 4). Video analysis indicated that subjects often cut left-hand curves in spite of the precise instruction to keep the car in lane. This behavior increased Sdlat. Effects of ethanol on Sdlat differed depending on the kind of road (Figure 4).

In the linear mixed models, a poorer lane tracking performance is indicated by a higher Sdlat score. Table 4 presents

Table 4. Effects of ethanol on lane keeping behavior on the right-hand bends of the rural road (linear mixed model, $N=17$ )*

\begin{tabular}{|c|c|c|c|}
\hline \multirow{2}{*}{ Parameter } & \multicolumn{2}{|c|}{$\begin{array}{l}\text { Effects of ethanol } \\
\text { on lane keeping behavior }\end{array}$} & \multirow{2}{*}{$\mathrm{p}$} \\
\hline & estimate (score) & SE & \\
\hline Intercept & 0.290 & 0.185 & 0.137 \\
\hline Session 1 & $-* *$ & - & - \\
\hline Session 2 & 0.009 & 0.034 & 0.789 \\
\hline Blood alcohol level (\%) & 2.244 & 1.067 & 0.058 \\
\hline Alcohol tolerance (ordinal scale $0-100$ ) & -0.003 & 0.002 & 0.235 \\
\hline \multicolumn{4}{|l|}{ Karolinska Sleepiness Scale score } \\
\hline at arrival & -0.029 & 0.035 & 0.432 \\
\hline
\end{tabular}


Table 4. Effects of ethanol on lane keeping behavior on the right-hand bends of the rural road (linear mixed model, $\mathrm{N}=17)^{*}$ - cont.

\begin{tabular}{|c|c|c|c|}
\hline \multirow[t]{2}{*}{ Parameter } & \multicolumn{2}{|c|}{$\begin{array}{l}\text { Effects of ethanol } \\
\text { on lane keeping behavior }\end{array}$} & \multirow[t]{2}{*}{$\mathrm{p}$} \\
\hline & estimate (score) & SE & \\
\hline before the 1 st test drive & 0.001 & 0.016 & 0.927 \\
\hline maximum on highway & 0.005 & 0.033 & 0.885 \\
\hline at the end of highway & -0.014 & 0.030 & 0.662 \\
\hline maximum on rural road & -0.018 & 0.021 & 0.409 \\
\hline after rural road & 0.027 & 0.029 & 0.384 \\
\hline \multicolumn{4}{|l|}{ Simulator Sickness Questionnaire score } \\
\hline at arrival & 0.016 & 0.019 & 0.415 \\
\hline before the 1 st test drive & 0.003 & 0.005 & 0.527 \\
\hline at the end of highway & -0.003 & 0.002 & 0.257 \\
\hline after rural road & 0.002 & 0.003 & 0.555 \\
\hline
\end{tabular}

* Scores related to the 90th percentiles of Sdlat. For detailed explanation see chapter statistics, the higher the score, the poorer the lane keeping. ** Reference.

SE - standard error.
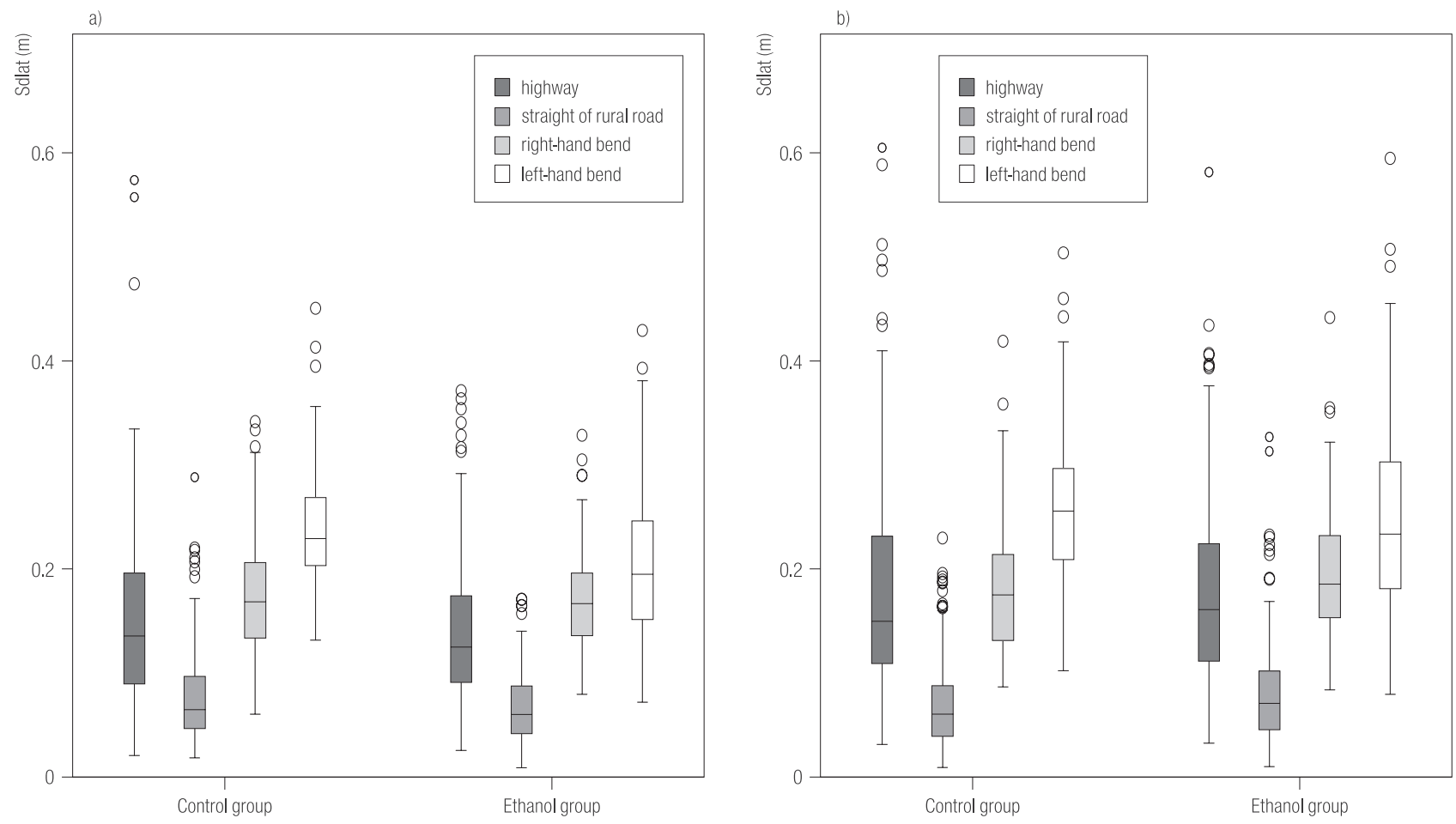

a) first test drive (all subjects were sober).

b) second test drive.

Fig. 4. Standard deviation of the lateral position (Sdlat) 
the relations between various influencing variables and the Sdlat score related to the 90th percentile of the righthand bends. An association with BAC was observed, but not with alcohol tolerance. This is also true for the score related to the 75 th percentile (estimate for $1 \%$ $\mathrm{BAC}=4.152, \mathrm{p}=0.055$, for alcohol tolerance: -0.003 and $p=0.458$, respectively). No association was observed between BAC and the 50th percentile score. Sdlat scores of other road segments were not associated with BAC. When SSQ scores were omitted from the linear mixed models, Sdlat scores of right-hand curves (75th percentile: $\mathrm{p}<0.05$, 90th percentile: $\mathrm{p}<0.001$ ) and straight sections (all $p<0.1$ ) were associated with BAC.

\section{DISCUSSION}

\section{Refinement of the driving simulation}

Prevention from simulator sickness and use of the Simulator Sickness Questionnaire

In this study, SSQ scores were relatively low and not associated with driving performance in the linear mixed models. We therefore conclude that our driving scenarios do not evoke noteworthy simulator sickness in screened young male test subjects. This conclusion might also be valid for young women (data not shown), who had low scores in preliminary experiments. Older subjects are more prone to simulator sickness than younger ones [26-28]. Therefore, our results cannot be extrapolated to older people. The Simulator Sickness Questionnaire [14] is considered as the gold standard for monitoring [1]. Until this date no other measurement has been proven to be superior to the SSQ [29]. Kennedy and colleagues [14] suggested the usage of the 75th percentile of the Total Sickness Score obtained by flight simulations on the first hop as a cutoff point. The rationale was that the 75 th percentile was the midpoint of the part of the study population that was affected by exposure. The 75th percentile corresponded to a score of 15 . To our knowledge no data on sensitivity, specificity, and the predictive value have been published so far, leaving no sufficiently validated cut-off point which could facilitate the interpretation of measured scores. This issue also persists for other questionnaires measuring simulator sickness. Nevertheless, control for possible simulator sickness should be mandatory, for it might confound the data $[26,30]$.

With regard to our data, another issue arises. The Simulator Sickness Questionnaire has been validated for fit pilots but not for persons with an impairment of health or fitness [14]. So far, the questionnaire has not been validated for monotonous driving conditions which may induce sleepiness. In this study it is striking that total SSQ scores were higher on the highway than on the rural road, despite the fact that a drive on the rural road seems more suitable to induce simulator sickness in sensitive test subjects. The highway was straight and without ongoing traffic except for the congestion at the end. In contrast, the rural road contained curves, and subjects had to hit the brakes repeatedly when they performed the reaction tests. Subjects perceived the highway as monotonous. Monotony resulted in an increase in sleepiness scores (Table 2). Accordingly, subjects appeared a bit more sleepy at the end of the highway ride when being monitored on the screen. The SSQ contains the items "fatigue" and "difficulty concentrating". Ability to concentrate may be impaired by sleepiness. When calculating sum scores without these two items, the resulting sum scores on the highway were not higher than those on the rural road at the first course and only slightly higher at the second one. Therefore we conclude that the increase of total SSQ scores on the highway was due to an increase in driver sleepiness. Thus, the monotonous highway drive falsely caused elevated SSQ scores with regard to possible simulator sickness. This issue could be of more significance if a very drowsy drivers' performance is investigated. The solution is not trivial because sleepiness itself may increase the susceptibility to simulator sickness. 


\section{Training on the driving simulator}

In this pilot study, mean braking reaction time declined by $86 \mathrm{~ms}$ in the second test drive. The improvement indicates a learning effect. The duration of training was one hour in total and braking was intensively exercised. In future studies, the training on our simulator has to be intensified. Data on learning behavior in driving simulations are sparse. Often practice sessions of up to $15 \mathrm{~min}$ have been reported in other studies [31,32]. The results of driving simulation studies should be controlled for possible training effects.

\section{The validity of the driving scenario}

Results of the mixed models assume that driving performance was impaired after alcohol ingestion. As analyses are explorative but not confirmatory, results must be interpreted using content-related criteria. Our results are consistent with other studies on ethanol effects $[15,16,33]$. Impairment of braking reaction time after ethanol ingestion is obvious. Adverse ethanol effects on Sdlat have been observed in drivers of real cars, with blood alcohol concentrations ranging between $0.04 \%$ and $0.07 \%$ [34-37]. In this study, the strongest associations between BAC and lane keeping behavior were observed on right-hand curves, but not on left-hand ones. Subjects often cut lefthand curves. This behavior increases Sdlat considerably and might mask the effect of ethanol. In order to reduce cutting the left-hand curves, well timed opposing traffic could be included in randomly selected curves. Lane keeping is easier on straight sections than on right-hand curves (Figure 4). Even a relatively low BAC might impair driver performance if the task requires high accuracy [33]. The increase of Sdlat on right-hand curves, but not on straight sections following ethanol intake is in line with these findings. Alcohol tolerance was not associated with driving performance in the mildly intoxicated subjects. This finding reflects our study design, as abstainers and heavy drinkers were excluded.
The rise of the median sleepiness score after the highway drive indicates that the highway was sufficiently monotonous. This can save time in future experiments when effects of sleepiness are to be investigated. On the other hand, the observed increase in sleepiness after a short time is a drawback with respect to validity. Participants are generally aware that they are not subjected to real danger and will not fight against possible sleepiness to the utmost. Logically, in a comparative study subjective sleepiness scores and line crossings following sleep restriction were higher in simulator drivers than in real car drivers [38]. The difference between real life and virtual reality must be taken into account when driving performance in simulators is interpreted.

The reaction time after the appearance of the donkey was longer than that of the deer, resulting in more crashes. This difference is plausible, because the contrast between the deer and its surroundings was higher. In contrast to our preliminary tests, the number of crashes with donkeys was much larger than with men. Different possible causes have to be discussed. As men moved quicker, they were inserted $90 \mathrm{~m}$ instead of $80 \mathrm{~m}$ in front of the car. The advantage of $10 \mathrm{~m}$ is partially depleted by the reaction time to man, which was on the average $203 \mathrm{~ms}$ longer. During that time, the car moves $5.64 \mathrm{~m}$, assuming a speed of $100 \mathrm{~km} / \mathrm{h}$. In addition, it was not until the center of the object appeared that the measurement of reaction time was recorded. This means that attentive subjects could recognize a large part of the donkey before the measurement started. In contrast, a much smaller portion of humans was visible when the registration of reaction time began.

The sooner an object is recognized the shorter the stopping distance. It is not feasible to calculate a distance reflecting the difference in perception. Nevertheless, it is clear that at least a part of the remaining $4.36 \mathrm{~m}$ is used. Altogether, the high number of crashes with donkeys cannot be adequately explained by the driving scenario. In the 
preliminary tests, some subjects spontaneously expressed their shock after colliding with a man, but were not disconcerted when they caused an accident with an animal. Possibly, subjects of the pilot study hit the brakes stronger when a man appeared. Unfortunately, the simulation software acquires only the maximum braking pressure but not the time course of pressure. Therefore, we cannot prove this hypothesis.

Expression of shock means an emotional engagement of subjects. In very general terms, the success of a given virtual reality is thought to be associated with the subjective sense of "being there". This feeling is widely referred to as presence [39]. The meaning of the term "presence" has been generalized to the illusion of being at a distant place $[40,41]$. The feeling of presence is an argument for the external validity of a simulation. With respect to scenarios in our driving simulation, this applies to the braking maneuvers, but less to the monotonous highway driving.

\section{Limitations of the study}

This is a pilot study with a limited number of test subjects. Nevertheless, a clear-cut ethanol effect on braking reaction time was observed. Subjects were only young males. Therefore, a possible generalization requires more research. Further experiments are necessary to validate the driving scenarios. After having completed the experiments, some subjects reported that they were interested in gathering the experience of driving when intoxicated. To avoid a selection bias, allocation to the subgroups was randomized. Subjects were told after the first experimental session, i.e. one hour before the second test drive, to which subgroup they were assigned. No one terminated the experiment after being allocated to the ethanol or control group. As it was clear that subjects would experience the symptoms of ethanol intoxication, no attempt of blinding was made. The lack of blinding is a limitation in this type of study design.

\section{CONCLUSION}

The observed ethanol effects lead to the conclusion that the applied scenario is also a suitable means to investigate the effects of other compounds, drugs and driver sleepiness.

The development of simulator sickness should be prevented as far as possible by creating appropriate scenarios. As simulator sickness cannot be avoided with certainty, it must be controlled for. Screening of test subjects for possible simulator sickness is recommended.

In addition, the level of drowsiness should be controlled during driving simulation. An appropriate training can minimize learning effects during the experiment. As there is little knowledge on learning curves, at least possible learning behavior during the experiment should be controlled as well.

\section{ACKNOWLEDGEMENT}

The study was funded by grant from the „Europäische Forschungsvereinigung für Umwelt und Gesundheit im Transportsektor e.V.“ (EUGT). The Kombi/DOA10-Schnelltest ${ }^{\oplus}$ for drug screening was provided by Mahsan Diagnostika. The authors are grateful to J. Adler ( $\dagger$ ) and G. Schwarz for careful technical assistance and to Dipl. Stat. U. Krahn, Institute of Medical Biostatistics, Epidemiology and Informatics, (IMBEI), University Medical Center of the Johannes Gutenberg University of Mainz, for valuable statistical advice. The authors are grateful to M. Melia for the linguistic finalization.

\section{REFERENCES}

1. Classen S, Bewernitz M, Shechtman O. Driving simulator sickness: An evidence-based review of the literature. Am J Occup Ther. 2011;65(2):179-88, http://dx.doi.org/10.5014/ ajot.2011.000802.

2. Hell W. [Falling asleep as a cause of accident. Occurence and prevention of road accidents due to sleepiness]. 
Berlin: Verkehrstechnisches Institut der Deutschen Versicherer; 2004. German.

3. Horne JA, Reyner LA. Sleep related vehicle accidents. Brit Med J. 1995;310(6979):565-7, http://dx.doi.org/10.1136/ bmj.310.6979.565.

4. Philip P, Vervialle F, Le Breton P, Taillard J, Horne JA. Fatigue, alcohol, and serious road crashes in France: factorial study of national data. Brit Med J. 2001;322(7290):829-30, http://dx.doi.org/10.1136/bmj.322.7290.829.

5. Connor J, Norton R, Ameratunga S, Robinson E, Civil I, Dunn R, et al. Driver sleepiness and risk of serious injury to car occupants: population based case control study. Brit Med J. 2002;324(7346):1125-9, http://dx.doi.org/10.1136/ bmj.324.7346.1125.

6. Maycock G. Sleepiness and driving: The experience of UK car drivers. J Sleep Res. 1996;5(4):229-37, http://dx.doi. org/10.1111/j.1365-2869.1996.00229.x.

7. Tregear S, Reston J, Schoelles K, Phillips B. Obstructive sleep apnea and risk of motor vehicle crash: systematic review and meta-analysis. J Clin Sleep Med. 2009;5(6):573-81.

8. Tregear S, Reston J, Schoelles K, Phillips B. Continuous positive airway pressure reduces risk of motor vehicle crash among drivers with obstructive sleep apnea: systematic review and meta-analysis. Sleep. 2010;33(10):1373-80.

9. Antonopoulos CN, Sergentanis TN, Daskalopoulou SS, Petridou ET. Nasal continuous positive airway pressure (nCPAP) treatment for obstructive sleep apnea, road traffic accidents and driving simulator performance: A metaanalysis. Sleep Med Rev. 2011;15(5):301-10, http://dx.doi. org/10.1016/j.smrv.2010.10.002.

10. Chiang WK, Chan CC, Tseng CT, Wang JD. Reduction of post-shift traffic injuries among gasoline station workers: Are they related to the reduction of occupational gasoline vapor exposure? Accid Anal Prev. 2005;37(5):956-61, http:// dx.doi.org/0.1016/j.aap.2005.04.016.

11. Ramaekers JG. Antidepressants and driver impairment: empirical evidence from a standard on-the-road test. J Clin Psychiatry. 2003;64(1):20-9.
12. Brunnauer A, Laux G. [Effects of psychoactive drugs on car driving ability]. Dtsch Med Wochenschr. 2008;133 Suppl 2:S38-40, http://dx.doi.org/10.1055/s-2008-1081071. German.

13. Johnson DM. Simulator sickness research summary. U.S. Army Research Institute for the Behavioral and Social Science Ft. Rucker, Alabama; 2007 [cited 2012 June 20]. Available from: http://www.dtic.mil/cgi-bin/GetTRDoc?L ocation $=\mathrm{U} 2 \& \operatorname{doc}=$ GetTRDoc.pdf $\& A D=A D A 474304$.

14. Kennedy RS, Lane NE, Berbaum KS, Lilienthal MG. Simulator sickness questionnaire: An enhanced method for quantifying simulator sickness. Int J Aviat Psychol. 1993;3(3): 203-20, http://dx.doi.org/10.1207/s15327108ijap0303_3.

15. Moskowitz H, Fiorentino D. A review of the literature on the effects of low doses of alcohol on driving-related skills. Washington 2000 [cited 2012 June 20]. Available from: http://ntl.bts.gov/lib/26000/26000/26005/DOT-HS809-028.pdf.

16. Ogden EJ, Moskowitz H. Effects of alcohol and other drugs on driver performance. Traffic Inj Prev. 2004;5(3):185-98, http://dx.doi.org/10.1080/15389580490465201.

17. Deutsche Gesetzliche Unfallversicherung, editor. Prophylaxis in occupational medicine. Stuttgart: Gentner Verlag; 2007.

18. Kotterba S, Orth M, Happe S, Mayer G. [Expert opinions regarding daytime sleepiness in neurological diseases and obstructive sleep apnea syndrome]. Nervenarzt. 2007;78(8):861-70, http://dx.doi.org/10.1007/s00115006-2191-y. German.

19. Boylan SM, Cade JE, Kirk SF, Greenwood DC, White KL, Shires $\mathrm{S}$, et al. Assessing caffeine exposure in pregnant women. Br J Nutr. 2008;100(4):875-82, http://dx.doi.org/10.1017/ S0007114508939842.

20. Boyle LN, Tippin J, Paul A, Rizzo M. Driver performance in the moments surrounding a microsleep. Transp Res Part F Traffic Psychol Behav. 2008;11(2):126-36, http://dx.doi.org/ 10.1016/j.trf.2007.08.001. 
21. Risser MR, Ware JC, Freeman FG. Driving simulation with EEG monitoring in normal and obstructive sleep apnea patients. Sleep. 2000;23(3):393-8.

22. Arnedt JT, Wilde GJ, Munt PW, MacLean AW. Simulated driving performance following prolonged wakefulness and alcohol consumption: separate and combined contributions to impairment. J Sleep Res. 2000;9(3):233-41, http://dx.doi. org/10.1046/j.1365-2869.2000.00216.x.

23. Verster JC, Roth T. Standard operation procedures for conducting the on-the-road driving test, and measurement of the standard deviation of lateral position (SDLP). Int J Gen Med. 2011;4:359-71, http://dx.doi.org/10.2147/IJGM. S19639.

24. Akerstedt T, Gillberg M. Subjective and objective sleepiness in the active individual. Int J Neurosci. 1990;52(1-2):29-37.

25. Widmark EMP. [The theoretical foundation and the practical utility of the forensic medical determination of ethanol]. Berlin: Verlag Urban und Schwarzenberg; 1932. German.

26. Brooks JO, Goodenough RR, Crisler MC, Klein ND, Alley RL, Koon BL, et al. Simulator sickness during driving simulation studies. Accid Anal Prev. 2010;42(3):788-96, http://dx.doi.org/0.1016/j.aap.2009.04.013.

27. Edwards CJ, Creaser JI, Caird JK, Lamsdale AM, Chisholm SL. Older and younger driver performance at complex intersections: implications for using perception-response time and driving simulation. Proceedings of the Second International Driving Symposium on Human Factors in Driver Assessment, Training and Vehicle Design; Park City 2003 [cited 2012 June 20]. Available from: http://drivingassessment. uiowa.edu/DA2003/pdf/7_Creaserformat.pdf.

28. Dahmen-Zimmer K, Kostka M, Gelau C. Assessing proneness to simulator sickness in a fixed-base driving simulator. Adv Transportation Studies. 2008 [cited 2012 June 20];16: 23-8. Available from: http:/host.uniroma3.it/riviste/ats/sixteenth\%20issue/Dahmen\%20Zimmer\%2023-28\%20A.pdf.

29. Keshavarz B, Hecht H. Validating an efficient method to quantify motion sickness. Hum Factors. 2011;53(4):415-26, http://dx.doi.org/10.1177/0018720811403736.
30. Lerman Y, Sadovsky G, Goldberg E, Kedem R, Peritz E, Pines A. Motion sickness-like syndrome among tank simulator drivers. Isr J Med Sci. 1992;28(8-9):610-5.

31. McGehee DV, Lee JD, Rizzo M, Dawson J, Bateman K. Quantitative analysis of steering adaptation on a high performance fixed-base driving simulator. Transportation Research Part F: Traffic Psychology and Behaviour. 2004;7(3):181-96, http://dx.doi.org/10.1016/ j.trf.2004.08.001.

32. Burgard E. [Driving ability of aging subjects]. Ludwig-Maximilians-Universität München; 2005 [cited 2012 June 20]. Available from: http://edoc.ub.uni-muenchen.de/4478/1/ Burgard_Esther.pdf. German.

33. Krüger H-P. [Absolutely unfit for driving - The false BAC limit of 1.0\%o]. Blutalkohol. 1990;27:182-201. German.

34. Brookhuis KA, de Waard D. The use of psychophysiology to assess driver status. Ergonomics. 1993;36(9):1099-110, http://dx.doi.org/10.1080/00140139308967981.

35. Vermeeren A, O'Hanlon JF. Fexofenadine‘s effects, alone and with alcohol, on actual driving and psychomotor performance. J Allergy Clin Immunol. 1998;101(3):306-11, http:// dx.doi.org/10.1016/S0091-6749(98)70240-4.

36. Gawron VJ, Ranney TA. The effects of alcohol dosing on driving performance on a closed course and in a driving simulator. Ergonomics. 1988;31(9):1219-44, http://dx.doi. org/10.1080/00140138808966764.

37. Louwerens JW, Gloerich ABM, De Vries G, Brookhuis KA, O‘Hanlon JF. The relationship between driver's blood alcohol concentration (BAC) and actual driving performance during high speed travel. In: Noordzij PC, Roszbach R, editors. Alcohol, Drugs and Traffic Safety - T86. Amsterdam: Elsevier; 1987. p. 183-6.

38. Philip P, Sagaspe P, Taillard J, Valtat C, Moore N, Akerstedt T, et al. Fatigue, sleepiness, and performance in simulated versus real driving conditions. Sleep. 2005;28(12):1511-6.

39. Baumgartner T, Speck D, Wettstein D, Masnari O, Beeli G, Jancke L. Feeling present in arousing virtual reality worlds: prefrontal brain regions differentially 
orchestrate presence experience in adults and children.

Front Hum Neurosci. 2008;2:8, http://dx.doi.org/10.3389/ neuro.09.008.2008.

40. Biocca F. The Cyborg's Dilemma: Progressive embodiment in virtual environments. J Computer-Mediated
Communication. 1997;3(2):1-18, http://dx.doi.org/10.1016/ S0923-8433(99)80011-2.

41. Schultze U. Embodiment and presence in virtual worlds: A review. J Inf Techno. 2010;25:434-49, http://dx.doi. org/10.1057/jit.2010.25.

This work is available in Open Access model and licensed under a Creative Commons Attribution-NonCommercial 3.0 Poland License - http://creativecommons.org/ licenses/by-nc/3.0/pl/deed.en. 